\title{
A cidade e o lugar: concepções, implicações e possibilidades no desenvolvimento da política habitacional
}

\section{Naiara Videira dos Santos ${ }^{1}$ e Edila Arnaud Ferreira Moura ${ }^{2}$}

\begin{abstract}
1 Mestranda em Sociologia e Antropologia pela Universidade Federal do Pará, Especialização em Metodologia do Ensino de Filosofia e Sociologia pelo Instituto Brasileiro de Pós-Graduação e Extensão, Especialização em Metodologia do Ensino da História e Geografia pela Faculdade Internacional de Curitiba, Especialização em Gestão do Sistema Único de Assistência Social pela Faculdade da Amazônia, graduada em Ciências Sociais pela Universidade Federal do Amapá e graduada em Comunicação Social pela Faculdade Estácio de Sá. Socióloga na Secretaria de Estado de Inclusão e Mobilização Social do Governo do Amapá, Brasil.

E-mail: nay-videira@hotmail.com $\mathcal{G}$ http://lattes.cnpq.br/5276635069320774 1 http://orcid.org/0000-0001-8464-3713

2 Doutorado em Desenvolvimento Socioambiental pela NAEA/UFPA e Professora Titular de Sociologia da Universidade Federal do Pará, Brasil.

E-mail: eafmoura@gmail.com 9 http://lattes.cnpq.br/2154370107837866 http://orcid.org/0000-0003-0093-8464
\end{abstract}

RESUMO: Este trabalho apresenta uma revisão de literatura sobre o desenvolvimento da política habitacional pensada a partir da concepção da cidade e do lugar, elementos intrínsecos para o seu planejamento e operacionalização. Como procedimento metodológico adota-se a pesquisa bibliográfica, tendo por base as discussões de teóricos das ciências sociais no que tange ao entendimento sobre as noções de cidade e de lugar, para então pensar a política de habitação ancorada a esses conceitos e suas correlações. Nesse sentido, este estudo tem por objetivo discutir a importância de se compreender parte dos elementos que estão presentes na formação e construção desses espaços, como sendo fundamentais para o desenvolvimento da política habitacional, assim como, também o reconhecimento do lugar, como espaço de construção de subjetividades, e dessa maneira, possa-se efetivar uma política pública visando à melhoria na qualidade de vida. $\mathrm{E}$, faz-se ainda uma breve contextualização da política habitacional brasileira, discutindo a importância das categorias cidade e de lugar na formulação dessa política pública.

Palavras-chave: Identidade; Território; Moradia.

The city and the place: conceptions, implications and possibilities in the housing policy development

ABSTRACT: This work refers to a literature review about housing policy development thought from de conception of the city and the place, intrinsic elements for the planning and operationalization. As methodological procedures we used bibliographic researches, it having as base the discussions of theorists within the scope of the social sciences with regard to the understanding about what is the city and what is the place and this way thinking the housing policy from these concepts and their correlations. In this sense, the present study discusses the importance of understanding all these elements that are present in the formation and constructions of these spaces as being essential to the housing policy development, as well as the recognition of the place as a place of construction of subjectivity and on this way it can really a public policy aiming the improvement in the quality of life. And, a brief contextualization of the Brazilian housing policy is also discussed, discussing the importance of the categories city and place in the formulation of this public policy.

Keywords: Identity; Territory; Housing. 


\section{INTRODUÇÃO}

Discutir a política habitacional requer pensar a cidade e o lugar como elementoschave deste processo. Mas afinal, o que é a cidade? Que significado possui o lugar? Há diferença entre a cidade e o lugar? Como se desenvolve esse processo dentro da política de habitação? São questões que o presente trabalho tenta responder a partir de uma reflexão teórica nas ciências sociais e mediante um contexto de globalização.

Para efeitos de análise, começa-se pela compreensão do conceito de cidade no contexto das sociedades capitalistas, uma vez que, nesse processo, o espaço urbano adquire novas significações e funcionalidades. Calvino descreve a cidade "como um todo no qual nenhum desejo é desperdiçado e do qual você faz parte, e, uma vez que aqui se goza de tudo o que não se goza em outros lugares, não resta nada além de residir nesse desejo e satisfazer" (CALVINO, 2016, p. 16). A cidade, assim, aparece como um lugar de relações materiais e subjetivas, por conseguinte, como espaço de existência social e humana.

A análise do lugar, por sua vez, perpassa pela ampliação da concepção de espaço geográfico, como sendo um local fixo, imutável e fechado, pressupondo uma conjuntura dialética de relações intra e extraterritoriais, portanto, espacialidades complexas e interligadas.

Assim, tem-se como objetivo discutir os conceitos de cidade e de lugar tomando como base os teóricos das ciências sociais, para se então pensar a política de habitação ancorada a esses conceitos e suas correlações. E, também, a partir uma breve contextualização do processo de desenvolvimento da política habitacional brasileira, busca-se discutir a importância das categorias de cidade e de lugar para uma melhor efetivação dessa política pública.

Como procedimentos metodológicos, realizou-se uma pesquisa bibliográfica, buscando sintetizar algumas das contribuições dos clássicos da Sociologia, como Durkheim (1999), Max Weber (1999), Karl Marx (2003), Engels (2007), Simmel (2009) e as abordagens da Escola de Chicago (NorteAmericana), na conceituação e discussão sobre a cidade, bem como os autores contemporâneos Beck (1999), também sobre a concepção de cidade, Boaventura de Souza Santos (2010) e Arturo Escobar (2005) com seus estudos sobre a concepção de lugar, e Bauman $(2005,2003,2001)$ com suas discussões tanto sobre a cidade como sobre o lugar.

\section{A CONCEPÇÃO DE CIDADE NA VISÃO DOS CLÁSSICOS E CONTEMPORÂNEOS NAS CI- ÊNCIAS SOCIAIS}

Partindo da concepção de cidades com base nos clássicos da Sociologia, Durkheim (1999), ao fazer uma análise da sociedade burguesa, decorrente da Revolução Industrial, define a cidade como resultante da necessidade dos indivíduos estabelecerem permanentemente o contato mais íntimo uns com os outros, e que só pode se estender e se multiplicar a partir da intensificação da densidade moral. Assim, Durkheim (1999) procurou demonstrar que muitos mais do que efeitos econômicos, a divisão do trabalho cumpriria uma função moral, possibilitando a coesão social, pois, através da necessidade de especialização de funções, os indivíduos desenvolveriam vínculos intensificados e dependentes, visto que 
com o aumento do volume social $^{1}$ nasceria o habitante das cidades. Dessa maneira, as cidades se constituiriam em espaços próprios de sociedades, onde predominaria a solidariedade orgânica ${ }^{2}$, a qual tem por fundamento a divisão social do trabalho, não existindo, assim nas sociedades inferiores, nas quais se desenvolveria a solidariedade mecânica ${ }^{3}$.

Weber (1999) apresenta a noção de que a cidade constitui um campo de relações de poder, determinado historicamente e em contextos específicos. Deste modo, a cidade não se restringe apenas a uma relação econômica, mas também a uma relação política. Logo, concebe a cidade como um tipo ideal ${ }^{4}$, uma categoria de análise de sua so-

${ }^{1}$ Durkheim (1999) atribui a densidade moral e o volume social aos fatores que gerariam a divisão social do trabalho, nesse sentido, o volume social refere-se a capacidade do indivíduo em maior proximidade de agir e reagir uns em relação aos outros.

${ }^{2}$ Solidariedade Orgânica típica das sociedades modernas desenvolvidas, tendo por base a divisão social do trabaIho. Nesse sentido, supõe que os indivíduos se diferem uns dos outros, e assim, só sendo possível se cada indivíduo tiver uma a esfera de ação própria, por conseguinte, uma personalidade. (DURKHEIM, 1999).

${ }^{3}$ Solidariedade mecânica, próprias das sociedades primitivas, onde há uma forte consciência coletiva partilhada pelos membros de uma mesma comunidade, e sendo determinante na maneira como os indivíduos estabelecem as suas relações com as pessoas e os objetos: " 0 que justifica essa denominação é que o vínculo que une o indivíduo à sociedade é todo analágo ao que liga a coisa a pessoa. A consciência individual, considerada sob esse aspecto, é uma simples dependência do tipo coletivo e segue todos os seus movimentos, como o objeto possuído segue aqueles que seu proprietário the imprime". ( DURKHEIM, 1999, p. 107 )

${ }^{4}$ Para Max Weber, os tipos ideais são modelos heurísticos de interpretação que utiliza na análise de sua sociologia compreensiva. Assim, "O tipo deve ser ideal, puro, para então fazer uso da casuística sociológica. Construção de médias, de tipos médios: 'quanto mais nítida e inequivocamente se construam esses tipos ideais, quanto mais alheios do mundo esteja, neste sentido, tanto melhor prestarão seu serviço, terminológica, ciologia compreensiva.

[...] nessas observações de uma "política econômica urbana", um "território urbano" e "autoridades urbanas" já indica que o conceito de "cidade" ainda pode e deve ser incluído em outra série de conceitos, além das categoriais econômicas até agora mencionadas exclusivamente - a saber: nas categorias políticas (WEBER, 1999, p. 415).

Marx e Engels (2007), partindo de uma crítica das sociedades capitalistas, como geradora do processo de exploração e produção da mais-valia ${ }^{5}$, ressaltam que a cidade moderna se constituiria como um local de produção e reprodução do capital, sendo resultante do modo de produção e das relações de produção existentes em uma dada sociedade. Assim, apresentando a cidade em uma relação de contraposição ao campo, destacam:

A cidade já é obra da concentração da população, dos instrumentos de produção, do capital, do desfrute e das necessidades, ao passo que o campo representa o expoente cabal ao fato contrário, quer dizer, ao isolamento e à solidão (MARX; ENGELS, 2007, p. 75).

Simmel (2009), por sua vez, busca analisar as relações sociais que se estabelecem nas cidades grandes, destacando o caráter blasé perante o individualismo e o embotamento em relação à diferenciação das coisas, como as relações mediadas pelo dinheiro: "A cidade constitui-se da totalidade de seus efeitos, que ultrapassam o seu ime-

classificatória bem como heuristicamente" (WEBER, 2009, p. 13).

${ }^{5}$ Em sua obra o "Capital", Marx (2003 a) define maisvalia como o excedente das horas trabalhadas não pagas ao trabalhador que são apropriadas pelo capitalista, contribuindo para a acumulação de capital por parte dos proprietários.

https://periodicos.unifap.br/index.php/estacao Macapá, v. 8, n. 1, p. 09-20, jan./abr. 2018 
diatismo. Só esse é o seu âmbito real, no qual se exprime o seu ser" (SIMMEL, 2009, p. 15).

Em uma abordagem contemporânea, Giddens (1991), embora não se encontre um conceito explícito de cidade, aponta para relação de esvaziamento do tempo e do espaço, cujos mecanismos de desencai$\mathrm{xe}^{6}$, definidos como os sistemas peritos e as fichas simbólicas, têm determinado as relações de confiança que permeiam a vida cotidiana do indivíduo. Nesse sentido, as cidades assumem um duplo aspecto, de um lado, pressupõem a segurança, através do desenvolvimento que a modernidade proporcionou, e por outro lado, implicam uma relação de risco, em decorrência das próprias incertezas que essa mesma modernidade gera.

Em condições de modernidade, a confiança existe no contexto de: (a) a consciência geral de que a atividade humana - incluindo nesta expressão o impacto da tecnologia sobre o mundo material - é criada socialmente, e não dada pela natureza das coisas ou por influência divina; (b) o escopo transformativo amplamente aumentado pela ação humana, levado a cabo pelo caráter dinâmico das instituições modernas. O conceito de risco substitui o de fortuna, mas isto não porque os agentes nos tempos pré-modernos não pudessem distinguir entre risco e perigo. Isto representa, pelo contrário, uma alteração na percepção da determinação e da contingência, de forma que os imperativos morais humanos, as causas naturais e o acaso passam a reinar no lugar das cosmologias religiosas (GIDDENS, 1991, p.45).

\footnotetext{
${ }^{6}$ Giddens (1991, p. 31) conceitua como desencaixe "ao 'deslocamento' das relações sociais de contextos locais de interação e sua reestruturação através de extensões indefinidas de tempo-espaço".
}

Para Ulrich Beck (1999), as cidades, como constituintes de uma sociedade globalizada, não estão mais delimitadas por fronteiras territoriais, mas fazendo parte de complexo de relações econômicas, políticas, sociais, culturais e ambientais que se estendem a nível global. Assim, Beck (1999, p. 29) define por globalidade, a ideia de que "já vivemos há tempos em uma sociedade mundial, ao menos no sentido de que a ideia de espaços isolados se tornou fictícia".

Já Bauman (2001), em suas pesquisas dentro de um contexto que denominou de Modernidade Líquida ${ }^{7}$, a cidade se apresentaria como um espaço onde as contradições e os dilemas da globalização se manifestam, assim, problemas ambientais, sociais, políticos, econômicos e religiosos que se desenvolvem no ambiente macro, afetam, consequentemente, também o micro local. $\mathrm{E}$, ainda ressalta, como uma das características das cidades, a convivência entre indivíduos estranhos uns aos outros, mas que estão em constante proximidade, o que gera um sentimento de medo e de incerteza, pois este estranho/outro é visto como ameaça:

[...] os espaços públicos, por sua vez, são lugares por excelência em que os desconhecidos se concentram e onde irrompem as características da vida urbana, onde ela alcança sua expressão máxima e onde percebemos tudo o que a diferencia de outros tipos de existência coletiva (BAUMAN, 2001, p. 67).

Assim, a busca por segurança constitui-se como princípio fundamental para a vida nas

\footnotetext{
${ }^{7}$ Termo utilizado por Bauman (2001) para designar uma nova fase da modernidade, caracterizada pelo caráter fluído, efêmero e amorfo nas relações no mundo contemporâneo, em contraposição a Modernidade Sólida que representaria o caráter estável e duradouro entre os sujeitos e as instituições sociais.
} 
cidades, onde o medo e a incerteza dominam as relações cotidianas. Dessa maneira, Bauman (2001) ressalta o caráter sedutor das cidades, em decorrência das novidades que se apresentam e, ao mesmo tempo, repulsam pela existência da incerteza e do medo.

Já os pensadores da Escola de Chicago, nos Estados Unidos, e entre eles Robert Park e Louis Wirth, desenvolveram a concepção da cidade como problema, ou seja, a ideia de cidade caótica, gerada pelo intenso processo de industrialização e urbanização, na virada do século $X I X$ para o $X X$, sendo necessária a busca de soluções concretas para os problemas existentes. A Escola de Chicago, fazendo usos de conceitos da geografia e também da biologia de Darwin, traz uma nova abordagem da cidade, em especial, para a questão da espacialidade urbana, criando mapas explicativos sobre a centralidade e a periferia. Assim, tanto em suas vertentes ecológicas e culturalistas, aborda a questão da cidade como um fenômeno per se, compreendendo-a como um variante individual. (SANT'ANNA, 2003)

Das diferentes abordagens do conceito de cidade, pode-se inferir que muito mais do que um espaço delimitado por fronteiras territoriais ou de administração política, a cidade aparece como espaço privilegiado para a constituição das relações econômicas, políticas, culturais, sociais, ambientais, dentre outros. Destaca-se também que no mundo globalizado, a cidade assume um papel fundamental, pois ela não desaparece, pelo contrário, adquiri novas formas de se significar e de se ressignificar diante das variadas formas que capitalismo global impõe.

\section{PENSANDO O LUGAR/ TERRITÓRIO NAS CIDADES}

Refletir sobre a cidade requer ao mesmo tempo pensar o lugar, embora em alguns momentos, dependendo da perspectiva de abordagem, a cidade se mescle com o lugar. Porém, é necessário pensar o lugar em suas particularidades e complexidades advindas do processo de formação das sociedades modernas contemporâneas, o que necessita situá-lo numa dimensão de espaço, de tempo, de representações e de relações, ultrapassando o conceito de fronteiras delimitadas, e, muita das vezes, ultrapassando a ideia de cidade em si, embora esta, também apresente, conforme discutido anteriormente, elementos complexos inseridos num conjunto de relações.

Neste sentido, a ideia de território como espaço de vivências, de relações, de trabaIho, de vida e, portanto, de constituição de subjetividades, emergindo como um lugar resultante do modo como as pessoas se apropriam e se percebem nesses espaços, levando-os a formação de uma rede de significações de identidade e de vínculos.

Para Bauman (2001), o lugar é concebido em um contexto de relações fluídas e efêmeras, próprias da Modernidade Líquida. Logo, os lugares constituem-se em locais de interações superficiais, pressupondo o estranhamento do outro, ou seja, a evitação de contatos mais duradouros e íntimos. Vive-se uma época de desengajamento, marcadas pelo distanciamento tempo-espaço e de configurações espaciais extraterritoriais.

Se a proximidade física não puder ser evitada, ela pode pelo menos ser despida da ameaça de "estar juntos" que contém com seu convite ao encontro significativo, ao diálogo e à inte- 
ração. Se não puder ser evitado o encontro com estranhos, pode-se pelo menos tentar evitar maior contato (BAUMAN, 2001, p. 133).

Assim, segundo Bauman (2001), em contraposição ao ideal de lugar, tido como um ponto de referência e de vida, o que existe na Modernidade Líquida é o não lugar, este marcado pela ausência de identidades, de história e de relações, pois "Jamais na história do mundo os não lugares ocuparam tanto espaço" (BAUMAN, 2001, p. 131).

Bauman (2001) ressalta igualmente a presença da formação de espaços vazios, os quais são destituídos de significação e, simplesmente, não existem, porque são invisíveis para a sociedade, como é o caso dos espaços ocupados pelas populações mais miseráveis.

O conceito vazio do lugar está no olho de quem vê e nas pernas e rodas de quem anda. Vazios são lugares em que não se entra e onde se sentiria perdido e vulnerável, surpreendido e um tanto atemorizado pela presença de humanos. (BAUMAN, 2001, p. 133).

Nesta perspectiva do lugar, Bauman (2003) trata a questão da Comunidade ${ }^{8}$, esta em sua concepção tradicional não se realizaria em tempos de Modernidade Líquida, pois a predominância das relações sociais do individualismo, consumismo, relações voláteis, levam cada vez mais, a segmentação da sociedade e a supremacia do individualismo como modos de construção de subjetividades.

Assim, a produção de uma identidade comunitária, noção extremamente valiosa para a ideia de comunidade, vem sendo substituída por uma identidade própria da sociedade de consumo capitalista. Logo, o

\footnotetext{
${ }^{8}$ Caracterizada pela ideia clássica de pertencimento, bem coletivo, projeto comunitário (BAUMAN, 2003).
}

lugar, no mundo atual, segundo Bauman (2003), enquanto comunidade se configura muita mais por uma busca de segurança diante das incertezas e dos perigos que rodeiam os indivíduos, frente à incapacidade de se constituir como um lugar de vivências, de ideal coletivo, em virtude das novas formas de sociabilidade que estão sendo construídas nas sociedades modernas.

Santos (2010), em seus estudos póscoloniais ou pós-modernismo de oposição ${ }^{9}$, identifica a ideia dos lugares fora do lugar, trabalha com a questão do lugar como uma relação de poder, que subjuga o outro, o diferente, com base em epistemologias dominantes do mundo ocidental desenvolvido.

Segundo Santos (2010), o universalismo é a base ideológica em que se assenta a gestão da desigualdade e da exclusão, apresentando-se sob duas formas: o universalismo antidiferencialista - que se caracteriza por negar a existência das diferenças, e nesse caso reproduz a desigualdade e a exclusão pelo excesso de semelhança; e o universalismo diferencialista - que radicaliza as diferenças, sendo a reprodução da exclusão e da desigualdade em decorrência do excesso de diferença.

Assim, esse sistema de pertença hierarquizado da desigualdade e de exclusão determina a forma como os lugares são percebidos e reconhecidos enquanto produtos de uma geopolítica do conhecimento.

\footnotetext{
${ }^{9}$ Conforme Santos (2010, p. 28): “Conjunto de correntes teóricas e analíticas, com forte implantação nos estudos culturais, mas hoje presente em todas as ciências sociais, que têm em comum darem primazia teórica e política às relações desiguais entre o Norte e o Sul na explicação ou na compreensão do mundo contemporâneo [...] A perspectiva pós-colonial parte da ideia de que, a partir das margens ou das periferias, as estruturas de poder e de saber são mais visíveis".
} 
A desigualdade e a exclusão são dois sistemas de pertença hierarquizada. No sistema de desigualdade, a pertença dá-se pela integração subordinada enquanto no sistema de exclusão a pertença dá-se pela exclusão. A desigualdade implica um sistema hierárquico de integração social. Quem está em baixo está dentro e a sua presença é indispensável. Ao contrário, a exclusão assenta um sistema igualmente hierárquico, mas dominado pelo princípio da segregação: pertence-se pela forma como se é excluído. (SANTOS, 2010, p. 280).

Na abordagem dos lugares fora do lugar, Santos (2010) identifica três grandes descobertas matriciais do segundo milênio. A primeira está relacionada ao Oriente como sendo o lugar da alteridade, sendo "o Oriente lugar cuja descoberta descobre o lugar do Ocidente" (SANTOS, 2010, p.182), e assim o chamado Orientalismo ${ }^{10}$ tem dominado a concepção que se desenvolveu sobre Oriente a partir das sociedades Ocidentais. A segunda distingue o selvagem como lugar de inferioridade, sendo o seu valor medido tão somente pela utilidade, em que o continente Americano e Africano são o lugar de excelência do selvagem. Por fim, a terceira identifica a natureza como lugar de exterioridade.

Tal abordagem reflete a forma como se concebe os diferentes lugares a partir de uma perspectiva dominante de conhecimento, nesse caso, de uma epistemologia centrada no Centro/Norte. Assim, evidencia-se "o sentimento de urgência é o resulta-

\footnotetext{
10 Edwaird Said (2007) conceitua Orientalismo, como disciplina em que o Oriente, com suas práticas e descobertas, é objeto de estudo sistemático, além de se referir a um conjunto de significações, tais como linguagem, sonhos, imagens que cada indivíduo elabora quando se reporta ao Oriente. Assim, o orientalismo como termo genérico, apresenta-se como uma visão ocidental do Oriente.
}

do da acumulação de múltiplas questões na mesma hora e no mesmo lugar. Sob o peso da urgência, as horas perdem minuto e os lugares comprimem-se" (SANTOS, 2010, p. 190).

Já Arturo Escobar (2005), também considerado um pós-colonialista, faz uma retomada da discussão sobre da ideia de lugar no mundo globalizado, buscando verificar as implicações decorrentes desse processo na forma como o indivíduo se relaciona com a cultura, com a economia, com o conhecimento e com a natureza, além de apresentar maneiras de resistências diante do seu desaparecimento e enfraquecimento em tempos da modernidade global. Escobar concebe o lugar como sendo o "outro" da globalização, onde aquele, nesse processo, é destituído de significação, havendo a supremacia do espaço ligado ao global, sobre o lugar que em geral, está associado ao local.

Nesse sentido, Escobar (2005) retoma o conceito de lugar de Levebre, como um espaço vivido, no qual os indivíduos atribuem significação, e, portanto, antagônico a concepção capitalista e da globalização que se situa em um cenário sem o sentido de tempo e de espaço. Dessa maneira, o lugar se estabelece como espaço de vivências, assumindo diversas formas de organização política e cultural, e, em muitos casos de resistência frente ao fenômeno da globalização.

A discussão de Escobar (2009) sobre o lugar retoma uma importante questão, pois implica em problematizar os espaços estabilizadores de poder e de diferença existentes nas sociedades globais, visto que não há dúvidas de que o lugar não está desvirtuado dos processos de mercantilização econômica e cultural, no entanto, reconhecer a sua 
existência e os processos de identidade, que se formam, possibilita estabelecer novas formas de se significar e de se relacionar com a sociedade e com a natureza.

Em termos gerais, o que é mais importante, destes modelos do ponto de vista do lugar, é que se poderia afirmar que constituem um conjunto de significados-uso que, apesar de existir em contextos de poder que incluem cada vez mais as forças transnacionais, não pode ser reduzido às construções modernas, nem ser explicado sem alguma referência a um enraizamento, aos limites e à cultura local. Os modelos de cultura e conhecimento baseiam-se em processos históricos, linguísticos e culturais, que, apesar de que nunca estão isolados das histórias mais amplas, porém retém certa especificidade do lugar (ESCOBAR, 2005, p. 138).

A discussão apresentada sobre o lugar pelos diferentes autores nas ciências sociais possibilita compreender esses espaços como dotados de significações, os quais adquirem em determinado contexto social, político, econômico e ideológico especificidades em que se formam uma rede de relações, redes de poder e de subjetividades.

No que se refere à política habitacional, a constituição da categoria do lugar, como elemento de análise e de discussão, tornase primordial para uma abordagem mais completa e condizente com as necessidades do território em desenvolvimento.

E tratando, especificamente da política habitacional brasileira, a importância das categorias de lugar, e também de cidade abordada anteriormente, tanto nas suas etapas de planejamento e de operacionalização torna possível desenvolver uma política pública considerando as especificidades das cidades, dos lugares, e com isso, seus atores, vivências, subjetividades, e práticas.
Mas, para uma maior compreensão desse cenário brasileiro se faz necessário contextualizar o surgimento da política habitacional no país, e ressaltar a importância das categorias cidade e lugar como elementos fundamentais para um desenvolvimento mais efetivo da respectiva política pública.

\section{A POLÍTICA HABITACIONAL SOBRE UMA PESRPECTIVA DA CIDADE E DO LUGAR}

A política nacional de habitacional ${ }^{11}$ no Brasil vem sendo implementada por diferentes governos, seja com maior abertura política, de ditadura militar ou de doutrina neoliberal. Dessa maneira, o investimento e a priorização de construção ou financiamento de moradias, para um dado segmento populacional, correspondem em cada período histórico aos interesses econômicos, políticos, sociais e ideológicos dominantes na sociedade brasileira.

Historicamente, o processo de urbanização das cidades brasileiras está ligado à industrialização na virada do século XIX para o XX, quando houve uma intensa migração de ex-escravos e migrantes europeus em busca de trabalho nas fábricas, gerando um processo de crescimento desordenado nas cidades. Vivencia-se, então, desde esse período, o aumento por demanda habitacional e de infraestrutura, até então inéditas nas sociedades brasileiras.

O desenvolvimento da política pública de habitação no país se acentua na década de 1930, quando o processo de industrializa-

\footnotetext{
${ }^{11}$ A Política Nacional de Habitação obedece a princípios e diretrizes que têm como principal meta garantir à população, especialmente a de baixa renda, o acesso à habitação digna, e considera fundamental para atingir seus objetivos a integração entre a política habitacional e a política nacional de desenvolvimento urbano.
} 
ção e de urbanização se intensifica, no entanto, trata-se de uma política direcionada a atender o segmento populacional de trabalhadores com carteira assinada, que reivindicavam perante o empresariado, o aumento de salários, como alternativa para os elevados aluguéis. No Governo Vargas (1930-1945) foi criado o Instituto de Aposentadoria e Pensões (1937) visando financiar casas destinadas ao aluguel, tratava-se de medidas paliativas e segregacionistas, pois excluía a maior parte da população de baixa renda, que vivia em condições precárias de moradia.

Com a criação da Fundação da Casa Popular - FCP (1946) começou-se a delinear uma política habitacional direcionada para a população de baixa renda, no entanto, ainda com ações bastante tímidas no setor. No Governo de Juscelino Kubitschek (19561961), marcado por um acelerado crescimento industrial, principalmente com a instalação de montadoras no país e abertura de estradas, há um crescimento urbano, contudo, a ocupação do espaço urbano ocorre de maneira desigual, pois enquanto a classe média tem acesso aos financiamentos de apartamentos e bens imóveis, a população de baixa renda, por sua vez, ocupava cada vez mais, as áreas de favelas e periferias.

No Governo Militar, a partir 1964, a Fundação da Casa Popular foi extinta, sendo criado o Plano Nacional de Habitação com objetivo de promover e desenvolver ações no âmbito da política habitacional. Todavia, as principais medidas adotadas pelo Governo Militar foram as de combate ao crescimento desordenado das cidades, controlando dessa maneira, a expansão de áreas de favelas e de loteamentos ilegais. Dessa forma, os investimentos na área urbana foram direcionados para a cidade legal, ficando às demais regiões periféricas excluídas dessas ações.

Ainda, no Governo Militar, em 1967, foi criado o Banco Nacional de Habitação, o qual deveria atender ao financiamento de moradias, principalmente às famílias de classe baixa, e ao mesmo tempo promover o desenvolvimento econômico do país, no entanto, o que se percebeu foi sua incapacidade de atender o segmento populacional de baixa renda, priorizando o investimento para as famílias de classe média, denotando novamente um processo de segregação e exclusão das camadas mais pobres.

Com o processo de redemocratização do Brasil, a partir de 1988 e, diante de uma nova conjuntura econômica e política internacional, marcada, sobretudo, pelo surgimento do neoliberalismo, o direcionamento da política habitacional, assim como das demais políticas públicas, tem sofrido cada vez mais a interferência dos organismos internacionais. Além disso, a presença do capital privado, na figura de bancos e grandes construtoras, em detrimento do papel secundário do Estado na execução e formulação da política habitacional tem se constituído como uma das grandes marcas desse processo.

Sabe-se que, embora a política habitacional desenvolvida no país ao longo desse período visasse reduzir o déficit habitacional, os investimentos foram direcionados em sua maior parte para as famílias com renda de 3 a 10 salários mínimos, sendo que o maior déficit encontra-se entre famílias com renda de 0 a 3 salários mínimos. Ademais, a presença do capital privado tem determinado, gradativamente, como e onde deverão ser investidos os recursos na habitação, o que só acaba por agravar ainda 
mais o problema de moradia no país.

No Brasil, estima-se que atualmente exista um déficit habitacional de 5,8 milhões de moradias, sendo desse total $82 \%$ localizado na área urbana, em que $89 \%$ correspondem à população de baixa renda, a mais atingida pelos processos de desigualdade social (IBGE, 2010).

Atualmente, a Política Nacional de Habitação, instituída em 2004 pelo Ministério das Cidades, tem como principal instrumento o Sistema Nacional de Habitação de Interesse Social, o qual visa possibilitar a população de menor renda moradia digna e o acesso a terra urbanizada, além de objetivar integrar a política habitacional com as demais políticas setoriais, considerado este um dos grandes enclaves na efetivação da referida política pública.

Contudo, estudos realizados no campo da política habitacional têm demonstrado a necessidade de se considerar na sua formulação e implementação outros componentes que vão além da oferta de moradia em si. Nesse aspecto, a discussão sobre a cidade e o lugar como elementos intrínsecos desse processo, possibilitam uma compreensão de estruturas aparentemente invisíveis, mas que são um alicerce para o desenvolvimento de uma verdadeira política pública. Dessa forma, estão implícitos nessa análise, por exemplo, os atores, os canais, as relações, as identidades, as estruturas, dentre outros.

Partindo de uma concepção marxista, a cidade - muito mais do que o espaço geográfico de localização dos territórios a serem abrangidos pela política habitacional constitui como um espaço onde as contradições e as disparidades do modo de sociedade capitalista se manifestam de forma mais expressiva.
Por isso, critica-se o modelo de política habitacional hierarquizada, que não leva em consideração as particularidades dos lugares/territórios, com base numa perspectiva de que as necessidades e modos de vida são homogêneos. Há de se considerar, portanto, que existem diferentes tipos de cidade e, inclusive, que a maior ou menor presença do capital vai determinar de algum modo o direcionamento da política habitacional.

Ressalta-se, porém, que não se trata de negar o princípio da universalidade e da equidade social ${ }^{12}$ como parâmetros para o planejamento da política de habitação, mas sim, de que se deve considerar as cidades a partir de seus arranjos e organizações específicas, embora a lógica do sistema capitalista seja reduzir tudo a único modelo de configuração espacial.

Pensando o lugar na questão habitacional, este se apresenta também sob um ponto de vista de extrema importância, pois são nos lugares, também entendidos, nesta abordagem, como territórios, os espaços de vivências, de construções de subjetividades, em que os atores vão construir toda uma rede de significações e de relações existenciais e materiais. Logo, a ideia de lugar, no âmbito da política habitacional, requer um olhar sobre os sujeitos, sobre os processos, sobre a sociabilidade, sobre a identidade, ou seja, todos os fatores que envolvem a relação do indivíduo com o território em desenvolvimento, além das necessidades econômicas. Daí a importância de se problematizar o que significa o lugar, e para onde ele se estende, pois nele as pessoas

\footnotetext{
${ }^{12}$ Propõe-se com o paper que equidade social seja usada como sinônimo de justiça social ao referir-se a justiça na distribuição de benefícios tanto quanto de oportunidades para recipientes (CAMPBELL, 1988).
} 
constroem e reconstroem a sua existência.

Ressalta-se que não se trata aqui de uma visão idealizada do lugar, pois, sabe-se que em uma sociedade capitalista globalizada, as pessoas estabelecem menos laços com o lugar onde moram, trata-se, portanto, de se compreender que nesses espaços os indivíduos, independentemente do tipo de vida que levam, têm como ponto de referência, seja como momento de chegada ou de saída: "No admirável mundo novo das oportunidades fugazes e das seguranças frágeis, as identidades ao estilo antigo, rígidas e inegociáveis, simplesmente não funcionam" (BAUMAN, 2005, p. 33).

Ressalta-se, porém que em contraposição a essa mobilidade das classes médias e altas, e com isso a perda da identidade do lugar, as camadas mais pobres, por sua vez, acabam constituído com o lugar onde moram processos de identidade muito fortes, resultante, muitas vezes, da necessidade de se manterem unidos perante aos processos de exclusão e desigualdade a que estão submetidos.

Assim, no contexto da política pública de habitação, a concepção do lugar deve permear todo o processo de desenvolvimento, pois muito mais do que o local de materialização da política pública, ele se constitui como o seu ponto de partida, de meio e fim, estando num constante processo de alimentação e realimentação para novas intervenções do território em questão, e dessa maneira, possa-se efetivar uma política pública condizente com o princípio de igualdade e justiça social.

\section{CONSIDERAÇÕES FINAIS}

As concepções de cidade e de lugar, contidas nos estudos clássicos e nos contempo- râneos das Ciências Sociais, permitem a compreensão de um universo social marcado por similitudes, diferenças, complexidades e contradições. Em virtude disso, é imprescindível um olhar diferenciado para realidades que são apresentadas erroneamente sob a forma de um mundo compacto e homogêneo diante do interesse do capital.

Dessa maneira, a política de habitação, baseada numa perspectiva de se pensar a cidade, bem como o lugar, possibilita reconhecer esses espaços como constituintes de vivências, relações, configurações espaciais e temporais na implementação da política pública, para assim efetivar o direito à cidade e a melhoria na qualidade de vida.

Ressalta-se que não se trata de criar uma relação dual cidade x lugar, onde um desenvolveria um papel mais importante do que o outro, mas pelo contrário, parte-se de uma concepção da cidade como ambiente macro para o desenvolvimento da política habitacional, e o lugar, o espaço micro. Nesta visão, ambos estão em constante interação, ao mesmo tempo influenciado e influenciando o outro. Dessa maneira, pensar a política habitacional, em que a discussão requer conhecer essa cidade e conhecer esse lugar, pressupõe a formulação de uma política pública que permitirá o desenvolvimento do território em suas múltiplas dimensões.

No caso brasileiro, de suas cidades com suas contradições e fortes disparidades regionais, e lugares com modos de vivência e práticas em geral, também muito diversas, se faz importante uma política pública habitacional que contemple as suas realidades especificas, e, nesse sentido, a concepção de cidade e de lugar se tornam primordial para se pensar um desenvolvimento mais 
justo e igualitário, ao considerar os atores, as necessidades, as particularidades, as vivências, as subjetividades, e não se constituindo em apenas uma reprodução verticalizada, esta, em geral, resultante de uma visão reducionista de cidade/lugar como mercadoria.

\section{REFERÊNCIAS}

BAUMAN, Z. Identidade. Rio de Janeiro: Zahar, 2005.

. Comunidade: a busca por segurança no mundo atual, 2003.

. Modernidade Líquida. Rio de Janeiro: Zahar, 2001.

BECK, U. O que é Globalização? Equívocos do Globalismo: respostas à globalização. São Paulo: Paz e Terra, 1999.

BRASIL. [Constituição (1988)] Constituição da República Federativa do Brasil. Brasília: Senado Federal, Coordenação de Edições Técnicas, 2016.

CALVINO, I. As cidades invisíveis. São Paulo: Companhia das Letras, 1990.

DURKHEIM, É. Da divisão do trabalho social. São Paulo: Martins Fontes, 1999.

ESCOBAR, A. O lugar da natureza e a natureza do lugar: globalização ou pósdesenvolvimento? In: LANDER, E. (Org.). A colonialidade do saber: eurocentrismo e ciências sociais. Perspectivas latinoamericanas. Buenos Aires: Colección Sur Sur, CLACSO, 2005. p. 133-168

GIDDENS, A. As consequências da modernidade. São Paulo: Unesp, 1991.

IBGE. Instituto Brasileiro de Geografia e Estatística. Censo Demográfico, 2010.

MARX, K.; ENGELS, F. A ideologia alemã. Rio de Janeiro: Civilização Brasileira, 2007.

MARX, K. O capital: crítica da economia política, o processo de produção do Capital.
Rio de Janeiro: Civilização Brasileira, 2003a. Livro 1, $1 \mathrm{v}$.

. O capital: crítica da economia política, o processo de produção do Capital. Rio de Janeiro: Civilização Brasileira, 2003b. Livro 1, 2 v.

SAID, E. W. Orientalismo: o Oriente como invenção do Ocidente. São Paulo: Companhia das Letras, 2007.

SANT'ANNA, M. J. G. A concepção da cidade em diferentes matrizes teóricas das Ciências Sociais. Revista Rio de Janeiro, n.9, p9192, jan/abril.2003

SANTOS, B. S. A Gramática do tempo: para uma nova cultura política. 3. ed. São Paulo: Cortez, 2010.

SIMMEL, G. As Grandes Cidades e a vida do Espírito (1903). Covilha: LusoSofia, 2009.

WEBER, M. Economia e Sociedade: fundamentos da sociologia compreensiva. Brasília, DF: Ed. UnB; São Paulo: Imprensa Oficial do Estado de São Paulo, 1999. 2 v.

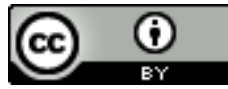

License information: This is an openaccess article distributed under the terms of the Creative Commons Attribution License, which permits unrestricted use, distribution, and reproduction in any medium, provided the original work is properly cited.

Artigo recebido em 24 de março de 2017.

Avaliado em 11 de janeiro de 2018.

Aceito em 16 de janeiro de 2018.

Publicado em 25 de maio de 2018.

\section{Como citar este artigo (ABNT):}

SANTOS, Naiara Videira dos; MOURA, Edila Arnaud Ferreira. A cidade e o lugar: concepções, implicações e possibilidades no desenvolvimento da política habitacional. Estação Científica (UNIFAP), Macapá, v. 8, n. 1, p. 09-20, jan./abr. 2018. 